\title{
Regulation of mitochondrial morphology and metabolism by Jak-STAT pathway
}

\author{
Kun Do Rhee* \\ Changpa Institute, Daegu University, Gyeongsan 38453, Korea
}

Received November 27, 2021

Revised December 14, 2021

Accepted December 16, 2021

\section{*Correspondence \\ Kun Do Rhee \\ E-mail:kdrhee@daegu.ac.kr}

Author's Position and Orcid no. Rhee KD, Visiting professor,

https://orcid.org/0000-0003-2886-468X

\begin{abstract}
Jak-STAT pathway is required for embryogenesis, female gametogenesis, cytokine-mediated neuroprotection, diabetes, obesity, cancer, stem cell, and various tissues. The noncanonical role of Jak-STAT in mitochondria function was supported by the detection of STAT protein in mitochondria, however, several studies show that STAT protein is detected in the endoplasmic reticulum (ER), and not in mitochondria. STAT protein may alter mitochondria function without entering mitochondria, this involves regulation of fission and fusion proteins to change mitochondria morphology. However, how changes in mitochondria morphology lead to changes in mitochondria metabolism needs further investigation.
\end{abstract}

Keywords: DRP1, fission, Jak-STAT, metabolism, mitochondria

\section{INTRODUCTION}

Signal transducer and activator of transcription 3 (STAT3) is one of seven STAT proteins that was first identified as an interleukin-6 (IL-6) dependent transcription factor inducing acute phase gene expression (Zhong et al., 1994). It was cloned and initially named as acutephase response factor (APRF) (Akira et al., 1994). STAT3 has an N-terminus domain, a coiled-coil domain, a DNA binding domain, a linker domain, an src homology 2 (SH2) domain, and a transactivation domain that contains tyrosine (Y705) and serine phosphorylation (S727) sites (Ihle, 1996). STAT3 are first tyrosine phosphorylated by receptor-associated Janus kinases (Jak), forms active dimers by Y705 binding to SH2 domain, and translocate to nucleus acting as a transcription factor to transcribe mitochondrial and metabolic genes as shown in Fig. 1 (Darnell et al., 1994; Schindler and Darnell 1995; Ihle, 1996; Levy and Lee 2002). In addition, STAT3 can be regulated by various post-translational modifications such as methylation, acetylation, and oxidation (Avalle and Poli 2018; Chun et al., 2020). Ablation of STAT3 results in embryonic lethality (Takeda et al., 1997) and expression of a constitutively active form of STAT3 (STAT3C) induces tumor formation (Bromberg et al., 1999). Disruption of Jak-STAT pathway shows its requirement in various tissues including female gametogenesis, embryogenesis, CNTF mediate neuroprotection in retinal degeneration, altered metabolism in an animal model of diabetes, and obesity (Levy and Lee 2002; Matthews and Febbraio 2008; Rhee et al., 2013; Sobinoff et al., 2013; Chowdhury et al., 2014; Gurzov et al., 2016). Thus, understanding the role of the Jak-STAT pathway in the regulation of mitochondria morphology and function may be crucial for finding treatments for infertility, neurodegenerative diseases, diabetes, obesity, and cancer. This review focuses on both the canonical and noncanonical role of the Jak-STAT pathway in mitochondrial morphology and metabolism. 


\section{NONCANONICAL ROLE OF JAK-STAT PATHWAY}

In addition to the canonical role of STAT3 as a transcription factor, several studies report noncanonical localization and function in the mitochondria as shown in Fig. 1 (Gough et al., 2009; Wegrzyn et al., 2009; Szczepanek et al., 2011; Zhang et al., 2013; Macias et al., 2014; Luo et al., 2016; Avalle and Poli 2018; Chun et al., 2020; Mohammed et al., 2020). These studies show that S727 phosphorylated STAT3 is detected in mitochondria by fractionation, confocal imaging, EM imaging, and protection from proteinase K. Deletion of STAT3 results in a decrease of electron transport chain (ETC) complex activities and glycolytic activity in ras transformed cells (Gough et al., 2009; Wegrzyn et al., 2009). Immunoprecipitation of mitochondrial extracts shows that complex I interact directly with mitochondrial STAT3 (mitoSTAT3) (Wegrzyn et al., 2009). Alternatively, mitoSTAT3 can bind directly to mitochondria DNA (Harbauer et al., 2014). ChIP assay using STAT3 antibody shows that STAT3 binds directly with mitochondrial DNA (Vassilev et al., 2002; Macias et al., 2014). DNaseI footprinting/protection assay shows the identification of STAT3 consensus recognition sequences in the human mitochondrial transcriptome (Mercer et al., 2011). In addition, other members of the STAT family also show mitochondria localization (Meier and Larner, 2014). Both immunofluorescence and immunogold electron microscopy show that STAT6-GFP is also detected in mito-

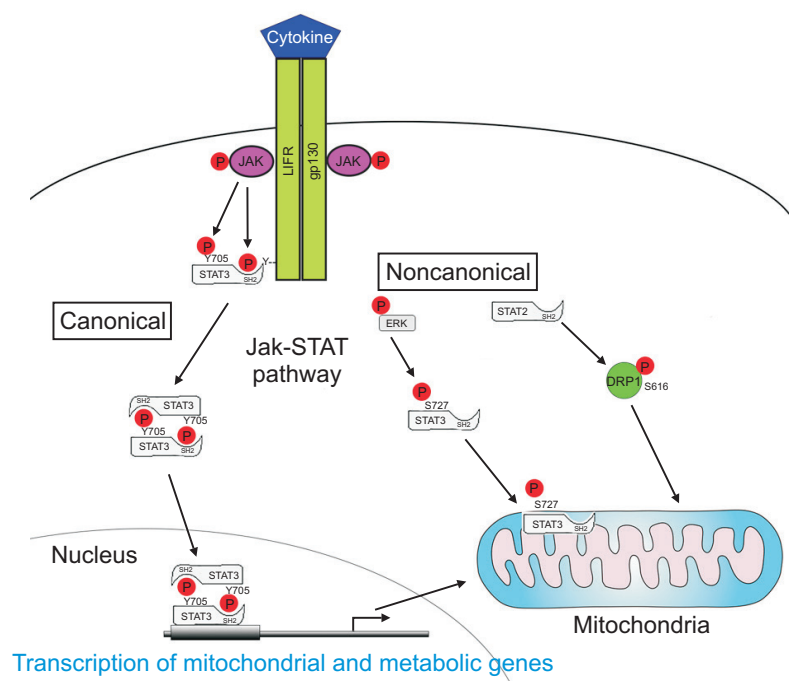

Fig. 1. Canonical and noncanonical Jak-STAT pathways. chondria (Khan et al., 2013).

Despite studies showing mitochondrial localization, several studies argue against mitochondria localization. First, STAT3 lacks mitochondria localization signal (Harbauer et al., 2014; Wiedemann and Pfanner 2017; Su et al., 2020). Second, even STAT3 enters mitochondria, the stoichiometry of STAT3 to mitochondrial protein nor genome is different for direct interaction to occur (Phillips et al., 2010). Third, recent studies show that STAT3 may not be found in mitochondria (Avalle et al., 2019; Su et al., 2020). Sucrose gradient centrifugation shows that STAT3 is only detected in mitochondria-ER and not in the pure mitochondrial fraction (Su et al., 2020). Thus, the localization of STAT3 protein in the mitochondria needs to be reexamined using higher resolution immunofluorescence microscopy and a better fractionation technique.

\section{REGULATION OF MITOCHONDRIAL MORPHOLOGY AND METABOLISM}

If STAT protein does not enter mitochondria, how can the Jak-STAT pathway regulate mitochondria metabolism? Studies show that the Jak-STAT pathway may regulate mitochondria metabolism via STAT3's canonical role as transcribing mitochondrial genes in the nucleus or act as a regulator of fission or fusion proteins to change mitochondrial morphology that alters cell metabolism as shown in Fig. 2. One of the phenotypes of STAT2 or STAT3 knockdown/knockout mice is the elongation of mitochondria (Shahni et al., 2015; Su et al., 2020). In cancer cells, proliferating cells show fragmented mitochondria morphology that exhibits the Warburg effect and the cells have diminished oxidative metabolism but increased glycolytic metabolism (Vander Heiden et al., 2009; Rafalski et al., 2012; Maycotte et al., 2017; Vaupel and Multhoff, 2021). The fragmented mitochondria morphology is not only limited to cancer, but also in proliferating stem cells. Embryonic stems cells (ESCs) maintain stemness and have fragmented mitochondrial morphology but change to elongated mitochondria morphology when it loses pluripotency during differentiation (Cho et al., 2006; Chung et al., 2007; Lee et al., 2020). Similar to cancer cells, the embryonic stem cells (ESCs) exhibit glycolytic metabolism but switch to oxidative metabolism upon differentiation (Chung et al., 2007; Kondoh et al., 2007). In addition, reprogrammed induces pluripotent stem (iPS) cells also 


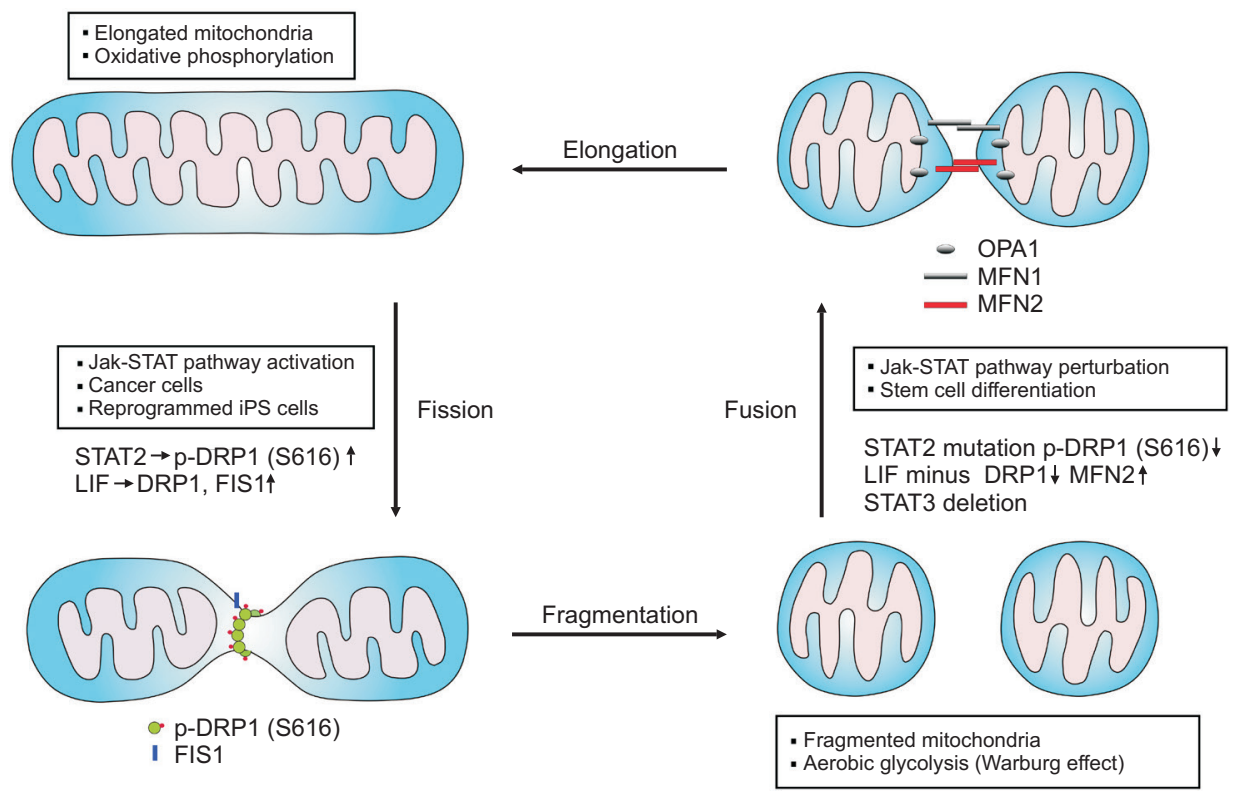

Fig. 2. Regulation of mitochondrial morphology and metabolism. switch from oxidative to glycolytic metabolism accompanied by mitochondrial fragmentation (Choi et al., 2015; Prieto et al., 2016).

How the Jak-STAT pathway regulates mitochondrial morphology is not clear. When mitochondria elongate upon withdrawal of leukemia inhibitory factor (LIF), dynamin-related protein 1 (DRP1) is decreased and fusion protein mitofusin 2 (MFN2) is increased, however other fusion/fission proteins mitofusin 1 (MFN1), optic atrophy protein 1 (OPA1), and mitochondrial fission 1 protein (FIS1) did not change (Lee et al., 2020). Knockdown of LIF receptor gp130 using RNA interference shows suppression of LIF induced DRP1 and FIS1, however, LIF induced DRP1 and FIS1 induction was inhibited by ERK1/2 inhibitor, but not by STAT3 small molecule inhibitor C1889 (Cho et al., 2006; Prieto et al., 2016; Fix et al., 2019). Cytokines can activate other pathways such as ERK and AKT via crosstalk (Boulton et al., 1994; Dolcet et al., 2001; Ernst and Jenkins, 2004), thus it is possible that LIF mediated ERK pathway may contribute to fission, and the use of small-molecule inhibitors may have not fully perturbed Jak-STAT pathway. Whole exome sequencing in a human patient with mitochondrial fission disorder revealed homozygous STAT2 mutation that is unable to phosphorylate DRP1 emphasizing the importance of the Jak-STAT pathway in mitochondrial fission (Shahni et al., 2015). However other studies show that STAT3 interacts directly with OPA1 in mitochondria using STAT3 small molecule inhibitor Sttatic (Zhang et al., 2020; Brillo et al., 2021) or binds to OPA1 promoter to induce fusion rather than fission using shRNA STAT3 knockdown and ChIP assay (Nan et al., 2017) contradicting the role of Jak-STAT pathway in maintaining mitochondria fragmentation. Contradicting studies suggest that the role of the Jak-STAT pathway may change depending on the tissue and microenvironment, however, these studies show the importance of the JakSTAT pathway in mitochondrial dynamics.

\section{FUTURE PERSPECTIVE}

The noncanonical role of STAT protein in mitochondria is still controversial. Super-resolution imaging using 3D structure illumination microscopy (SIM) may help to detect STAT protein in the mitochondria. Whether the Jak-STAT pathway induces fission via DRP1 or fusion via OPA1 is also controversial. The role of the Jak-STAT pathway may change depending on the tissue specificity and microenvironment. Studies show a link between mitochondrial morphology and metabolism, however, how changes in mitochondrial morphology regulate glycolytic and oxidative metabolism needs to be examined. Understanding the role of the Jak-STAT pathway in the regulation of mitochondria morphology and function may be crucial to finding treatments and diagnostics for various diseases. 
Author Contributions: Writing - original draft, K.D.R.; writing - review \& editing, K.D.R.

\section{Funding: None.}

Ethical Approval: Not applicable.

Consent to Participate: Not applicable.

Consent to Publish: Not applicable.

Availability of Data and Materials: Not applicable.

\section{Acknowledgements: None.}

Conflicts of Interest: No potential conflict of interest relevant to this article was reported.

\section{REFERENCES}

Akira S, Nishio Y, Inoue M, Wang XJ, Wei S, Matsusaka T, Yoshida K, Sudo T, Naruto M, Kishimoto T. 1994. Molecular cloning of APRF, a novel IFN-stimulated gene factor 3 p91related transcription factor involved in the gp130-mediated signaling pathway. Cell 77:63-71.

Avalle L, Camporeale A, Morciano G, Caroccia N, Ghetti E, Orecchia V, Viavattene D, Giorgi C, Pinton P, Poli V. 2019. STAT3 localizes to the ER, acting as a gatekeeper for ER-mitochondrion $\mathrm{Ca}^{2+}$ fluxes and apoptotic responses. Cell Death Differ. 26:932-942.

Avalle L and Poli V. 2018. Nucleus, mitochondrion, or reticulum? STAT3 à la carte. Int. J. Mol. Sci. 19:2820.

Boulton TG, Stahl N, Yancopoulos GD. 1994. Ciliary neurotrophic factor/leukemia inhibitory factor/interleukin 6/ oncostatin $\mathrm{M}$ family of cytokines induces tyrosine phosphorylation of a common set of proteins overlapping those induced by other cytokines and growth factors. J. Biol. Chem. 269:11648-11655.

Brillo V, Chieregato L, Leanza L, Muccioli S, Costa R. 2021. Mitochondrial dynamics, ROS, and cell signaling: a blended overview. Life (Basel) 11:332.

Bromberg JF, Wrzeszczynska MH, Devgan G, Zhao Y, Pestell RG, Albanese C, Darnell JE Jr. 1999. Stat3 as an oncogene. Cell 98:295-303.

Cho YM, Kwon S, Pak YK, Seol HW, Choi YM, Park DJ, Park KS, Lee HK. 2006. Dynamic changes in mitochondrial biogenesis and antioxidant enzymes during the spontaneous differentiation of human embryonic stem cells. Biochem. Biophys. Res. Commun. 348:1472-1478.

Choi HW, Kim JH, Chung MK, Hong YJ, Jang HS, Seo BJ, Jung TH, Kim JS, Chung HM, Byun SJ, Han SG, Seo HG, Do JT.
2015. Mitochondrial and metabolic remodeling during reprogramming and differentiation of the reprogrammed cells. Stem Cells Dev. 24:1366-1373.

Chowdhury SR, Saleh A, Akude E, Smith DR, Morrow D, Tessler L, Calcutt NA, Fernyhough P. 2014. Ciliary neurotrophic factor reverses aberrant mitochondrial bioenergetics through the JAK/STAT pathway in cultured sensory neurons derived from streptozotocin-induced diabetic rodents. Cell. Mol. Neurobiol. 34:643-649.

Chun KS, Jang JH, Kim DH. 2020. Perspectives regarding the intersections between STAT3 and oxidative metabolism in cancer. Cells 9:2202.

Chung S, Dzeja PP, Faustino RS, Perez-Terzic C, Behfar A, Terzic A. 2007. Mitochondrial oxidative metabolism is required for the cardiac differentiation of stem cells. Nat. Clin. Pract. Cardiovasc. Med. 4 Suppl 1:S60-S67.

Darnell JE Jr, Kerr IM, Stark GR. 1994. Jak-STAT pathways and transcriptional activation in response to IFNs and other extracellular signaling proteins. Science 264:1415-1421.

Dolcet X, Soler RM, Gould TW, Egea J, Oppenheim RW, Comella JX. 2001. Cytokines promote motoneuron survival through the Janus kinase-dependent activation of the phosphatidylinositol 3-kinase pathway. Mol. Cell. Neurosci. 18:619-631.

Ernst M and Jenkins BJ. 2004. Acquiring signalling specificity from the cytokine receptor gp130. Trends Genet. 20:23-32.

Fix DK, VanderVeen BN, Counts BR, Carson JA. 2019. Regulation of skeletal muscle DRP-1 and FIS-1 protein expression by IL-6 signaling. Oxid. Med. Cell. Longev. 2019:8908457.

Gough DJ, Corlett A, Schlessinger K, Wegrzyn J, Larner AC, Levy DE. 2009. Mitochondrial STAT3 supports Ras-dependent oncogenic transformation. Science 324:1713-1716.

Gurzov EN, Stanley WJ, Pappas EG, Thomas HE, Gough DJ. 2016. The JAK/STAT pathway in obesity and diabetes. FEBS J. 283:3002-3015.

Harbauer AB, Zahedi RP, Sickmann A, Pfanner N, Meisinger C. 2014. The protein import machinery of mitochondria-a regulatory hub in metabolism, stress, and disease. Cell Metab. 19:357-372.

Ihle JN. 1996. STATs: signal transducers and activators of transcription. Cell 84:331-334.

Khan R, Lee JE, Yang YM, Liang FX, Sehgal PB. 2013. Live-cell imaging of the association of STAT6-GFP with mitochondria. PLoS One 8:e55426.

Kondoh H, Lleonart ME, Bernard D, Gil J. 2007. Protection from oxidative stress by enhanced glycolysis; a possible mechanism of cellular immortalization. Histol. Histopathol. 22:8590.

Lee JE, Seo BJ, Han MJ, Hong YJ, Hong K, Song H, Lee JW, Do JT. 2020. Changes in the expression of mitochondrial morphology-related genes during the differentiation of murine embryonic stem cells. Stem Cells Int. 2020:9369268.

Levy DE and Lee CK. 2002. What does Stat3 do? J. Clin. Invest. 109:1143-1148.

Luo X, Ribeiro M, Bray ER, Lee DH, Yungher BJ, Mehta ST, Tha- 
kor KA, Diaz F, Lee JK, Moraes CT, Bixby JL, Lemmon VP, Park KK. 2016. Enhanced transcriptional activity and mitochondrial localization of STAT3 co-induce axon regrowth in the adult central nervous system. Cell Rep. 15:398-410.

Macias E, Rao D, Carbajal S, Kiguchi K, DiGiovanni J. 2014. Stat3 binds to mtDNA and regulates mitochondrial gene expression in keratinocytes. J. Invest. Dermatol. 134:19711980.

Matthews VB and Febbraio MA. 2008. CNTF: a target therapeutic for obesity-related metabolic disease? J. Mol. Med. (Berl.) 86:353-361.

Maycotte P, Marín-Hernández A, Goyri-Aguirre M, Anaya-Ruiz M, Reyes-Leyva J, Cortés-Hernández P. 2017. Mitochondrial dynamics and cancer. Tumour Biol. 39:1010428317698391.

Meier JA and Larner AC. 2014. Toward a new STATe: the role of STATs in mitochondrial function. Semin. Immunol. 26:2028.

Mercer TR, Neph S, Dinger ME, Crawford J, Smith MA, Shearwood AM, Haugen E, Bracken CP, Rackham O, Stamatoyannopoulos JA, Filipovska A, Mattick JS. 2011. The human mitochondrial transcriptome. Cell 146:645-658.

Mohammed F, Gorla M, Bisoyi V, Tammineni P, Sepuri NBV. 2020. Rotenone-induced reactive oxygen species signal the recruitment of STAT3 to mitochondria. FEBS Lett. 594:14031412.

Nan J, Hu H, Sun Y, Zhu L, Wang Y, Zhong Z, Zhao J, Zhang N, Wang Y, Wang Y, Ye J, Zhang L, Hu X, Zhu W, Wang J. 2017. TNFR2 stimulation promotes mitochondrial fusion via Stat3- and NF-kB-dependent activation of OPAl expression. Circ. Res. 121:392-410.

Phillips D, Reilley MJ, Aponte AM, Wang G, Boja E, Gucek M, Balaban RS. 2010. Stoichiometry of STAT3 and mitochondrial proteins: implications for the regulation of oxidative phosphorylation by protein-protein interactions. J. Biol. Chem. 285:23532-23536.

Prieto J, León M, Ponsoda X, Sendra R, Bort R, Ferrer-Lorente R, Raya A, López-García C, Torres J. 2016. Early ERK1/2 activation promotes DRP1-dependent mitochondrial fission necessary for cell reprogramming. Nat. Commun. 7:11124.

Rafalski VA, Mancini E, Brunet A. 2012. Energy metabolism and energy-sensing pathways in mammalian embryonic and adult stem cell fate. J. Cell Sci. 125:5597-5608.

Rhee KD, Nusinowitz S, Chao K, Yu F, Bok D, Yang XJ. 2013. CNTF-mediated protection of photoreceptors requires initial activation of the cytokine receptor gp130 in Müller glial cells. Proc. Natl. Acad. Sci. U. S. A. 110:E4520-E4529.

Schindler C and Darnell JE Jr. 1995. Transcriptional responses to polypeptide ligands: the JAK-STAT pathway. Annu. Rev. Biochem. 621-651.

Shahni R, Cale CM, Anderson G, Osellame LD, Hambleton S, Jacques TS, Wedatilake Y, Taanman JW, Chan E, Qasim W, Plagnol V, Chalasani A, Duchen MR, Gilmour KC, Rahman S. 2015. Signal transducer and activator of transcription 2 deficiency is a novel disorder of mitochondrial fission. Brain 138:2834-2846.

Sobinoff AP, Sutherland JM, Mclaughlin EA. 2013. Intracellular signalling during female gametogenesis. Mol. Hum. Reprod. 19:265-278.

Su Y, Huang X, Huang Z, Huang T, Xu Y, Yi C. 2020. STAT3 localizes in mitochondria-associated ER membranes instead of in mitochondria. Front. Cell Dev. Biol. 8:274.

Szczepanek K, Chen Q, Derecka M, Salloum FN, Zhang Q, Szelag M, Cichy J, Kukreja RC, Dulak J, Lesnefsky EJ, Larner AC. 2011. Mitochondrial-targeted Signal transducer and activator of transcription 3 (STAT3) protects against ischemia-induced changes in the electron transport chain and the generation of reactive oxygen species. J. Biol. Chem. 286:29610-29620.

Takeda K, Noguchi K, Shi W, Tanaka T, Matsumoto M, Yoshida N, Kishimoto T, Akira S. 1997. Targeted disruption of the mouse Stat3 gene leads to early embryonic lethality. Proc. Natl. Acad. Sci. U. S. A. 94:3801-3804.

Vander Heiden MG, Cantley LC, Thompson CB. 2009. Understanding the Warburg effect: the metabolic requirements of cell proliferation. Science 324:1029-1033.

Vassilev AO, Lorenz DR, Tibbles HE, Uckun FM. 2002. Role of the leukemia-associated transcription factor STAT3 in platelet physiology. Leuk. Lymphoma 43:1461-1467.

Vaupel P and Multhoff G. 2021. The Warburg effect: historical dogma versus current rationale. Adv. Exp. Med. Biol. 1269:169-177.

Wegrzyn J, Potla R, Chwae YJ, Sepuri NB, Zhang Q, Koeck T, Derecka M, Szczepanek K, Szelag M, Gornicka A, Moh A, Moghaddas S, Chen Q, Bobbili S, Cichy J, Dulak J, Baker DP, Wolfman A, Stuehr D, Hassan MO, Fu XY, Avadhani N, Drake JI, Fawcett P, Lesnefsky EJ, Larner AC. 2009. Function of mitochondrial Stat3 in cellular respiration. Science 323:793-797.

Wiedemann N and Pfanner N. 2017. Mitochondrial machineries for protein import and assembly. Annu. Rev. Biochem. 86:685-714.

Zhang Q, He L, Dong Y, Fei Y, Wen J, Li X, Guan J, Liu F, Zhou T, Li Z, Fan Y, Wang N. 2020. Sitagliptin ameliorates renal tubular injury in diabetic kidney disease via STAT3-dependent mitochondrial homeostasis through SDF-1 $\alpha$ /CXCR4 pathway. FASEB J. 34:7500-7519.

Zhang Q, Raje V, Yakovlev VA, Yacoub A, Szczepanek K, Meier J, Derecka M, Chen Q, Hu Y, Sisler J, Hamed H, Lesnefsky EJ, Valerie K, Dent P, Larner AC. 2013. Mitochondrial localized Stat3 promotes breast cancer growth via phosphorylation of serine 727. J. Biol. Chem. 288:31280-31288.

Zhong Z, Wen Z, Darnell JE Jr. 1994. Stat3: a STAT family member activated by tyrosine phosphorylation in response to epidermal growth factor and interleukin-6. Science 264:9598. 